\title{
Subjetividad revolucionaria y capital. A propósito del "libro" o "teoría" del trabajo asalariado
}

\author{
Revolutionary subjectivity and capital. Concerning the "book" or "theory" of \\ wage labor
}

\author{
Gabriel Rivas Castro*
}

\begin{abstract}
Resumen: Tomando como punto de partida el debate en torno al "libro" o "teoría" del trabajo asalariado de Marx, el presente trabajo busca echar algunas luces sobre el tema -aparentemente de carácter marxológico- con el objetivo acercarnos críticamente al problema de la potencia revolucionaria de la clase obrera, avanzando en su comprensión científica. Siguiendo los planteos de Marx y Juan Iñigo Carrera, esperamos mostrar los límites e implicancias que tienen las dos líneas que se identifican como dominantes en el tema específico descubriendo su carácter puramente ideológico, para así avanzar en una solución alternativa al problema.
\end{abstract}

Palabras clave: capital, clase obrera, trabajo asalariado, lucha de clases, fuerza de trabajo, reproducción, valorización.

Abstract: Taking as its starting point the debate about the "book" or "theory" of wage labor of Marx, this paper seeks to shed light on the subject -apparently a marxologic one- with the purpose of a critical approach to the problem of revolutionary potential of the working class, to advance in its scientific comprehension. Following the proposal of Marx and Juan Iñigo Carrera, we hope to show the limits and implications of the two lines identified as dominant regarding the specified topic, to discover its purely ideological character in order to advance in an alternative solution to the problem.

Keywords: capital, working class, wage labor, class struggle, labor force, reproduction, valorization.

Recibido: 2 abril 2016

Aceptado: 20 junio 2016

\footnotetext{
* Chileno, profesor de filosofía, magister en economía, Universidad Arcis, g.rivas@cipstra.cl Este artículo fue desarrollado a partir de la tesis con la cual se obtuvo el grado de magister en economía. Gracias a Tamara Seifer por sus correcciones y comentarios.
} 


\section{El libro del trabajo asalariado y el destino de la obra de Marx}

El presente artículo tiene como punto de partida un problema recurrente en la tradición marxista: el debate en torno al supuesto libro o teoría del trabajo asalariado que se remonta a la segunda década del siglo XX. Ya a fines del s. XIX, Kautsky publicó parte de los Grundrisse, donde Marx señaló expresamente una serie de "libros" a partir de los cuales se configuraría su plan de trabajo. Pero no será hasta inicios de la segunda década del siglo XX que autores como Wilbrand (Lapides 2008, 211), a partir de estas notas y los comentarios en la Contribución a la crítica de la economía política (Marx 2011), señalarán el carácter incompleto de la obra de Marx, atribuyéndole un lugar parcial a El Capital y relegándolo a tan sólo uno de una serie de libros incompletos. Este punto de partida ha sido un profuso problema en la tradición marxista desde entonces ${ }^{1}$. Sin embargo, la importancia de esta cuestión no tiene que ver con un interés "filológico", sino con dar cuenta de su importancia a la hora de conocer las determinaciones de la acción política de la clase obrera. Aquello que se presenta de inmediato como un problema meramente marxológico, aparece ahora como lo opuesto: un problema político. Tal como lo han señalado Starosta (Starosta, 2015), el problema de la subjetividad revolucionaria de la clase obrera se presenta en varios autores, incluidos los que tratamos en este artículo, como una de carácter trascendental o arraigado ontológicamente. De esta manera, según el argentino, el fundamento de la subjetividad revolucionaria -su potencialidad histórica- aparece estando por fuera de las formas alienadas a través de las cuales se realiza o afirma el proceso de vida humano, es decir, aparecen como determinaciones que escapan a la relación social general (Starosta 2015, 2-3). En última instancia, esta subjetividad subyace por fuera del capital y plantea un antagonismo radical que, en nuestra opinión, no termina siendo sino la inversión del objetivo planteado por los autores.

A pesar de sus diferencias, el conjunto de literatura revisada diverge a partir de un punto común evolutivo determinado por ciertas apreciaciones en torno a El Capital, tanto a su contenido como a su lugar en el conjunto de la obra de Marx. Por un lado destacan los autores que estiman que El Capital es sólo una parte en el conjunto de la obra de Marx, quien no desarrolló totalmente las determinaciones del trabajo asalariado, dejándolo pendiente para un libro diferente que no alcanzó a completar, como varios otros. Más allá de lo estrictamente filológico, la ausencia de este libro implica que la obra está incompleta respecto de las determinaciones de la subjetividad revolucionaria de la clase obrera dejando

\footnotetext{
${ }^{1}$ Después del texto de Wilbrand, existe una réplica de Grossmann donde analiza el desarrollo de los planes de trabajo de Marx (Grossmann, 2013) y considera a El Capital como una obra "esencialmente completa", quedando así sentadas las bases de las dos perspectivas dominantes sobre el tema. Junto a esta discusión, Grossmann también busca desarrollar el problema del salario en línea con su teoría del derrumbe capitalista en debate con la socialdemocracia alemana (Grossmann, 1979), Años más tarde, Rodolsky retomará la cuestión en los 60s bajo una perspectiva similar, pero mediada por una crítica a lo hecho por Grossmann (Rodolsky, 2004). Rubel, revivirá la perspectiva de Wilbrand -sin aportar mucho más- a principio de los 70s (Rubel, 2003), y será desarrollada por Negri al cerrar la década (Negri, 2001). Finalmente, entrando en los noventas el debate se re abre con la discusión entre Lepides (Lapides, 2002) (Lapides, 2008) -más cercano a lo hecho por Grossmann y Rodolsky- y Lebowitz (Lebowitz, 1992) (Lebowitz, 2006) -más en la línea de Wilbrand y Rubel.
} 
la puerta abierta a la búsqueda o desarrollo de una comprensión de la subjetividad revolucionaria de la clase obrera que no abarca la obra de Marx. Por otro lado, están los autores que sí estiman que la "teoría del trabajo asalariado" está contenida en El Capital. A partir de un exhaustivo análisis del desarrollo de la obra de Marx, este segundo grupo es capaz de determinar su recorrido intelectual y señalar cómo el plan original de fines de los 50 s cambia y se convierte en lo que conocemos como El Capital y sus borradores asociados, varios de los cuales integran temas que debieron haber sido tratados en los otros libros, de haberse mantenido el orden original. Sin embargo, en estos autores el problema de la subjetividad revolucionaria de la clase obrera desaparece al ser formulado como un problema puramente teórico o sin una relación muy clara con la acción política, algo que los diferencia de aquellos que buscan completar la obra bajo la urgencia que esta impone. Ambas posiciones nos parecen insuficientes, por lo que buscaremos avanzar en su superación.

\section{a. De lo que se trata es de interpretar a Marx}

Dentro del primer grupo de "teóricos del libro del trabajo asalariado", Maximiliano Rubel destaca como un punto de partida casi obligado para los autores que buscan avanzar en las faltas de la obra del maestro. Considerando su trabajo de re-ordenamiento de la obra de Marx, Rubel plantea una interpretación de todo el trabajo de Marx, buscando una relación de continuidad entre sus trabajos de "juventud" y los de "madurez", todo orientado por la lucha política sostenida por el francés contra el estalinismo y la ortodoxia marxista (Sartelli 2012, 13). Considerando los "planes" de trabajo de Marx esbozados a fines de los 50s y principios de los 60s señala, tal como mencionamos al principio, que "la crítica de la economía política ocuparía un opúsculo entre los demás” (Rubel 2003, 38). El plan de la "Economía" es algo que Marx no alcanzó a completar ${ }^{2}$, por lo que descartar un libro sobre el trabajo asalariado es contrario al plan original que, según Rubel, resulta orientado por un método específico que es inseparable del ordenamiento descrito en el plan de trabajo.

Como se sabe, los intereses de Rubel están puestos fundamentalmente en discutir con el marxismo oficial, cuestionando el "carácter de "sistema" de la obra de Marx" (Rubel 2003, 39), por lo que el grueso de su trabajo es un intento de ordenar la obra de manera tal que sea posible elaborar una interpretación de Marx que recupere su sentido original. Según el francés,

\footnotetext{
"es cierto que la fe en el "sistema" y a su "fundación" por los dos [Marx y Engels, G.R.] cumple una función bien precisa en el espíritu y en el comportamiento de los discípulos que rechazaron retomar el problema en el lugar donde Marx tuvo que dejarlo: dispensa volver a poner en cuestión las bases filosóficas de un socialismo bautizado "científico"” (Rubel 2003, 73).
}

\footnotetext{
${ }^{2}$ Rubel dice: “....ahora bien, Marx no solamente no acabará este ambicioso proyecto sino que, hacia el final de su vida, no habrá acabado siquiera su primer "opúsculo", más exactamente el primero de los escritos críticos previstos en su inicial plan de trabajo" M. Rubel, Marx sin mito, Barcelona, Octaedro, 2003, p 39.
} 
Para Rubel, el proyecto de Marx ha sido truncado por "la adhesión casi religiosa de varias generaciones de discípulos a la ficción de un "sistema marxista" [lo que] ha llevado a la muerte del diálogo que el autor de El Capital, obra inacabada y abierta, deseó continuar más allá de la tumba" (Ibíd.). En esta dirección, donde el problema es la interpretación de Marx, no puede dejar de culpar a Engels como el primer intérprete que cierra o intenta cerrar el "sistema". Según Rubel, el mejor amigo de Marx es el "principal codificador de la Weltanschauung marxista, Engels trazó el camino a los epígonos y a las futuras generaciones de adeptos. Involuntariamente, reconozcámoslo, ha encerrado y coagulado una especie de sistema, una teoría incompleta pero fértil de susceptibles deducciones y desarrollos" (Rubel 2003, 49). ${ }^{3}$ Rubel, en contra de Engels y demás discípulos, prefirió seguir defendiendo el texto contra sus falsos intérpretes.

Pero Rubel avanza un paso más allá y parece señalar que este carácter "fragmentario" de la obra -cuya unidad parece ser objeto de disputa de los diversos intérpretes-, su estado incompleto como "sistema", lo hace dudar del carácter científico del aporte de Marx al desarrollo de la acción política de la clase obrera (Rubel 2003, 41). Es más, indica que el proyecto de Marx nunca logró dar la prueba científica sobre la superación del modo de producción capitalista, reduciendo así el aporte de Marx a un "legado ético"4

Para Rubel, esta postergación corresponde a que "El Capital debía ser y continuar siendo un libro de sociología económica que analizara el papel de la clase de los capitalistas en el proceso de producción material; los otros dos libros debían analizar los respectivos papeles de los propietarios de la tierra y de los trabajadores asalariados" (Rubel 2003, 46). Es decir, El Capital se reduce a un libro de "sociología económica", a un libro que habla sobre el capital y los capitalistas. Por lo tanto, en lugar de haber un libro del trabajo asalariado más, aparte de este libro sobre el capital -esta segunda parte que se contradice con lo primero a lo que apelan -, existiría un tercer libro sobre la propiedad de la tierra y los terratenientes. De ahí que la totalidad aparezca, desde esta perspectiva, como una relación tripartita, donde cada forma existiría en relación a las otras dos, determinada por leyes propias. Para Rubel la clase obrera sigue siendo un misterio, El Capital nada dice sobre sus determinaciones, por lo que no puede evitar posicionar la lucha de clases en el centro, pero bajo una forma abstracta: un mandato ético ${ }^{5}$. En otras palabras, esta reducción de la lucha de la clase obrera a un horizonte ético -legado autromarxista que nunca lo abandona (Sartelli 2012, 8)- supone que esta queda por fuera de las determinaciones de $E l$ Capital. De esto es posible concluir dos cosas: por un lado, que la clase obrera es un "sujeto" diferente al capital (es decir, de su relación social general); por el otro, la necesidad

\footnotetext{
${ }^{3}$ Rubel, op. cit., 21.

${ }^{4}$ Como señala más adelante: "Y si no pudo aportar la prueba científica integral de la necesidad histórica del hombre por fin humano y de la sociedad por fin social, consiguió al menos llevar a cabo la demostración, subrayada cada día por la historia vivida, de la necesidad ética de una liberación que todas las utopías habían soñado antes que él" Rubel op cit. 82. En una nota Rubel trata a Marx como "teórico científico del movimiento obrero" y "su visionario ético", Rubel, op. cit. 91.

5 Ver, por ejemplo, Rubel, Karl Marx: Ensayo de Biografía Intelectual, 2012 o Rubel, Reflexiones sobre utopía y revolución, 1968
} 
de fundar éticamente la lucha de la clase obrera al carecer de relación necesaria con sus propia condiciones de reproducción ${ }^{6}$. Cabe agregar que sería esto también lo que explica el ordenamiento hecho por Rubel de la obra de Marx, arbitrario según algunos (Lapides 2008, 215), incluso en momentos en que el mismo Marx podría estar "de acuerdo" con su propio texto si tuviera que interpretarse (Sartelli 2012, 11).

Rubel, al reducir el "método" de Marx a una "sociología económica", relativiza su aporte científico y disocia el carácter revolucionario de la clase obrera de sus condiciones materiales, reduciendo su potencia revolucionara a un horizonte "ético". Para el francés, la "quintaesencia" de la obra de Marx, este método al cual Marx parece apegarse celosamente, señala la triada "del capital, de la propiedad de la tierra y del trabajo asalariado" como lo central y, por lo tanto, la relación que existe entre las diferentes formas descritas en cada supuesto libro, abriendo la puerta a su desarrollo posterior como un necesidad ineludible desde el punto de vista del proyecto incompleto de Marx, divorciando a la clase obrera de su relación social general: el capital, sustituyendo así su potencia material por un mandato ético.

\section{b. El Capital contra la clase obrera}

Por otro lado tenemos a Antonio Negri. En un texto que reúne una serie de lecciones impartidas en 1978 sobre los Grundrisse, expone sus posiciones en torno a este problema desde una reinterpretación del conjunto de lo que denomina "espíritu global de la obra de Marx” (Negri 2001, 20). En una línea similar a la de Rubel, para Negri, El Capital se presenta como una exposición parcial del conjunto de la obra marxiana, colocando en cuestión su importancia como el punto más elaborado de la investigación de Marx (Negri 2001, 20), y relevando la necesidad de avanzar en el conocimiento de las determinaciones faltantes en El Capital. Esto implica "bajar" al capital al nivel de otras determinaciones, ya que El Capital corresponde a la abstracción de "una parte" de la cuestión. Esta ausencia lo lleva a la "reinterpretación" del lugar del salario en el estudio de Marx y a relativizar la importancia de su obra principal (Ibíd.).

El carácter monolítico de El Capital no sólo estaría sobrevalorado, sino que estaría viciado "por una presentación categorial que con frecuencia limita y transforma su eficacia. [...] La objetivación de las categorías de El Capital bloquea la acción de la subjetividad revolucionaria." (Negri 2001, 21). El Capital, entonces, sería una obra cerrada y monolítica que no sólo no deja espacio a la subjetividad obrera, si no que bloquea la misma posibilidad de su acción política, a diferencia de los Grundrisse que, deslizado dentro de El Capital, nos entregaría una comprensión clara del carácter "antagonista del desarrollo" (Negri 2001, 32). En la sobrevalorada obra abundaría el objetivismo, la subjetividad revolucionaria estaría ausente, sólo estaría presente el capital. Más aún "El Capital es al mismo tiempo el texto que

\footnotetext{
6 Esta diferencia fundamental entre el capital y la clase obrera lo lleva a considerar los argumentos autonomistas de la "autoactividad" de la clase obrera. Ver su nota 62 (Rubel 2003, 92), bajo estas consideraciones parece que resulta más fácil entender que esta relación exterior es la fundante de su Marx "teórico del anarquismo" (Rubel 2003, 93).
} 
ha servido para reducir la crítica a teoría económica, para anular la subjetividad en la objetividad, para someter al proletariado subversivo a la inteligencia de recomposición y represión dominante" (Negri 2001, 33). Ahora resulta que El Capital no es sólo una parte de la obra, si no que opera en contra de la misma clase obrera, por lo que un libro del trabajo asalariado no sólo se justificaría desde un punto de vista filológico, sino que, dada la forma reaccionaria que adquiere El Capital como limitante de la acción política de la clase obrera, sería una necesidad política. Es así que "toda la teoría del capital únicamente podía ser fundada y desarrollada a partir de las modulaciones de la teoría del salario, a partir de lo que ella aludía, a partir de lo que contenía", es más, "el capítulo sobre el salario no constituye únicamente la fundamentación implícita, sino la trama del desarrollo de la teoría marxiana del capital" (Negri 2001, 149). Desde esta perspectiva, El Capital aparecería como una suerte de introducción a la obra magna: el libro del trabajo asalariado.

Ante esta ausencia de la subjetividad, falta de antagonismo, etc. es que Negri desea recuperar los Grundrisse para dar con lo racional del método, que define como "el aspecto teórico-práctico de la insurgencia revolucionaria" (Negri 2001, 16). A diferencia de El Capital, en el borrador "[...] asistimos [...] a un movimiento hacia delante, de la teoría, cada vez más coherente, dirigido a la identificación del momento fundamental que es el antagonismo obrero colectivo-capital colectivo, representado en la forma de la crisis" (Negri 2001, 17-18). En otras palabras, los Grundisse dan cuenta de un "antagonismo" ausente en El Capital al integrar la subjetividad al análisis del capital mismo, principal factor de la superación del modo de producción capitalista como relación social general.

Ahora, bajo la consideración de la subjetividad, Negri sobrescribe la teoría del plusvalor, mostrándola como el punto de encuentro entre el análisis objetivo del capital y subjetivo de la clase (Negri 2001, 22). De esta manera, es que re-aparece la subjetividad en el centro del capital, donde "todos los dualismos formales de los que se parlotea con frecuencia (análisis teórico del capital contra política, dialéctica contra materialismo, objetivismo y subjetivismo) se hallan aquí quemados y fundidos, por decirlo de alguna manera, en el dualismo real que constituye, en forma antagonista, el proceso del capital" (Negri 2001, 23). En El Capital no cabe la clase obrera. Por lo tanto, la forma de resolver esta falta de un libro del trabajo asalariado, que se abre por la necesidad de desarrollar y explicar en qué consiste esta subjetividad que Marx considera dentro del capital pero fuera de El Capital, consisten en "seguir la conexión que aproxima conceptualmente, a través de muchos fragmentos, la definición crítica del salario a la definición revolucionaria del comunismo y de la subjetividad comunista. Se trata, en suma, de concebir al menos el esquema del libro sobre el salario planificado por Marx, captando todas las articulaciones necesarias de éste" (Negri 2001, 25). Para hacer este recorrido hacia las "articulaciones" del libro sobre el trabajo asalariado, Negri se valdrá del método diseñado por Marx con el fin de "agregar" la subjetividad revolucionaria de la clase obrera (Ibíd.).

Para Negri, esta idea del "método" se resume en que - como la actividad subjetiva-, se hace parte de la definición de las estructuras, las cuales son descritas por Marx unilateralmente en El Capital. Como parte irreductible de la estructura, la subjetividad existe 
en relación con esa estructura, sobrescribiéndola por medio de su propia práctica como conciencia libre, independiente del capital. Estas consideraciones son las que posicionan a los Grundrisse como obra abierta, porque es la aplicación de este método lo que va señalando "el universo "plural" del método de Marx" (Negri 2001, 25). Estos borradores que insertan la subjetividad en medio del capital, "representa el centro del desarrollo teórico de Marx, porque representa el momento en el cual el sistema en formación no se cierra, sino que se abre a la totalidad de la práctica" (Negri 2001, 32).

Dada su vital importancia, Negri empieza a reconstruir el contenido de este libro del trabajo asalariado, es decir, avanza en la caracterización de una subjetividad obrera. Según Negri lo que deja de lado Marx en El Capital, por haberse dedicado a describir sólo una parte de la cuestión, son las determinaciones propias de la clase obrera. Los obreros, como un aspecto antagónico del capital no pueden ser reducidos a éste, por lo que se vuelve necesario caracterizarlos. Es así que "el proceso de valorización, empujado a esta dimensión totalitaria, debe dejar espacio a la emergencia de la autovalorización proletaria, a la expansión de su potencialidad antagonista" (Negri 2001, 146-147).

Desde esta nueva perspectiva, las leyes de El Capital emergen como apariencias; lo que se encuentra en el fondo racional es la subjetividad obrera, que debe ser caracterizada en tanto opuesta al capital, por lo tanto, regida por leyes diferentes a las suyas; por la necesidad de la autovalorización.

Negri señala que la subordinación del libro del trabajo asalariado a El Capital "no es verdad", "porque todos estos elementos no deben considerarse subordinados a las leyes del capital, sino a leyes de la lucha de clases" (Negri 2001, 148) ${ }^{7}$. La valorización contrapuesta entre el capital y la clase obrera se expresa ahora como lucha de clases, la cual tiene, incluso, sus propias leyes. Salta a la vista que esta relación antagónica que pone en movimiento la producción y reproducción de la vida material en su forma capitalista, se expresaría como una relación de exterioridad cuya forma más simple y directa es la extracción de plusvalor, resultado de esta tensión entre fuerzas subjetivas y objetivas. Para el autor, "es preciso repetirse porque la importancia fundamental del descubrimiento marxiano del plusvalor (y de las reducciones que lo constituyen) no puede agotarse en el libro sobre el capital" (Negri 2001, 148). Al estar gobernado el modo de producción capitalista por la lucha de clases, es necesario avanzar en determinar la especificidad de la autovalorización proletaria (Negri, 2001, pág. 146).

En este encuentro de fuerzas -que es la producción de plusvalor- expresa el punto de divergencia entre dos polos antagónicos. El Capital caracterizó sólo a uno de estos, el del capital, pero falta el segundo, el de la fuerza de trabajo: "el trabajo que produce, la fuerza de trabajo, no son un motor inmóvil a partir del cual se crea el capital: por el contrario, se despliegan a lo largo de todas las articulaciones del capital, animan contradictoriamente todas las objetivaciones del capital" (Negri 2001, 149). En tanto fuerza viva que se mueve,

\footnotetext{
${ }^{7}$ La cursiva es nuestra.
} 
parece ser una barrera absoluta, un límite, al capital. El salario, por tanto, representa el límite, el punto de entrada a esta nueva fuerza.

Al ser el establecimiento del trabajo necesario un producto de la lucha de clases, todo parece indicar que es el valor de uso quien opone resistencia en tanto tiene necesidades independientes y cuyo valor difiere del necesario para el capital. Mientras que uno necesita plusvalor, el otro, tiene sus necesidades independientes, se autovaloriza. Es un ser libre frente al capital, contrario a la pulsión de valorización de este último. La clase obrera aparece como su antagonista. Esta independencia esencial en el desarrollo de sus determinaciones sería lo que sitúa a los Grundrisse por sobre El Capital (Negri 2001, 151):

La tasa de plusvalor representa la relación entre el trabajo necesario y el plustrabajo. Cada uno de estos momentos se presenta como exterior. El trabajo necesario es irreductible por presentar la necesidad del obrero, el plustrabajo es la fuerza de El Capital como fuerza que constriñe y busca someter a la clase obrera. Por lo tanto, "únicamente el trabajo necesario tiene esta capacidad de oponer a la valorización capitalista una resistencia que es su misma (de sí mismo) conservación y reproducción” (Negri 2001, 154). Según Negri, "esta potencia subjetiva, es irreductible. El capital se halla obligado a reconocerse como relación, como proporción, como regla impuesta a una separación. La forma de la relación es por ambos lados la lucha. La lucha de clases, la política, se encuentran a partir de ahora en el centro de la teoría económica" (Negri 2001, 152). La irreductibilidad de la política puesta en el corazón del capital convierten al valor en una expresión de la lucha de clases, por lo que el capital es una relación social que se define, según el análisis de Negri, por organizar la producción social a partir de una relación social directa que se desarrolla en su forma más simple como valorizaciones contrapuestas (Negri 2001, 155).

En el lado de la clase obrera, Negri ve la reproducción de la fuerza de trabajo, sometida a la pequeña circulación (Marx 1971, 195), como el momento de la autovalorización obrera al suponer que "el dinero se subordina a la autovalorización” (Negri 2001, 157). En tanto el trabajador no busca si no el consumo, su reproducción supone su autovalorización, la que es contraria o antagonista a la del capital. El trabajador tiene necesidades, a eso se resume la crítica al capital: "El trabajo crea sus necesidades e impone al capital que las satisfaga" (Negri 2001, 151). Por lo tanto "se entiende plenamente qué puede ser en Marx el libro sobre el trabajo asalariado" (Negri 2001, 152). Para Negri, el desarrollo de la subjetividad obrera coloca y restituye al perdido trabajo sobre el salario al centro de la teoría marxiana. Según el autor "la teoría del salario se convierte en regla del desarrollo" (Negri 2001, 151). Restituida la política dentro del capital, "la forma del valor es puro simple poder de mando, pura y simple forma de la política" (Negri 2001, 167), es decir, fruto de una relación social directa.

Para "salvar" a la clase obrera Negri pierde de vista la especificidad del modo de producción capitalista, deformando el problema del valor de la fuerza de trabajo y su reproducción. Reduce la valorización a una relación de fuerzas exteriores, una forma concreta que toma la lucha de clases: por un lado, el capital con su necesidad de 
valorización, por el otro, los obreros que producen con vistas a su autovalorización fuera de la producción. El resultado de este antagonismo aparece en su determinación más simple como tasa de plusvalor. De esta manera, la tasa de plusvalor -que se forma como resultado del grado de explotación en la producción- depende de la correlación de fuerzas, por lo tanto, la lucha de clases antecede a la valorización. La política, relación directa entre personificaciones, es puesta en el centro de la teoría y explica al trabajo asalariado como el producto de una pura correlación de fuerzas, como formas contrapuestas de valorización, fruto del puro antagonismo. ¿Cuál es el valor de la fuerza de trabajo? Lo que la fuerza de trabajo pueda hacer valer en su lucha por auto-valorizarse. Una mera tautología. Desde esta perspectiva, la reflexión de Negri tiene una doble falla: deja sin explicar el objeto que problematiza y reduce su contenido a una pura abstracción. Es más, invierte las cosas colocando a las relaciones económicas indirectas como formas concretas de las relaciones políticas directas; planteando que la acumulación capitalista no está regulada por el plusvalor sino por el antagonismo de las clases. Nuevamente, el carácter revolucionario de la clase obrera, se comprende como una relación exterior al capital, obteniendo su fuerza a partir de propios intereses inmediatos que guían su autovalorización bajo una necesidad opuesta a su relación social general, regida por una abstracta conciencia libre.

\section{c. La economía política de la clase obrera}

En una línea complementaria a la de Negri encontramos a Lebowitz. El canadiense, a diferencia del italiano, trata de avanzar en una descripción más acabada de la economía política que, según estos autores, Marx no desarrolló. De esta forma, deduce ("dialécticamente") la necesidad de un libro en torno al trabajo asalariado. Al igual que Negri, lo hace siguiendo los planes de Marx en los Grundrisse (Marx 1971, 29-30) o bien a partir de lo citado en la Contribución... (Marx 2011, 3). Como sea, es quien más lejos lleva esta hipótesis escribiendo "una economía política de la clase obrera", como bien señala el título de su libro (Lebowitz 2006). Esta necesidad está fundada en una completa interpretación del trabajo de Marx, pero más específicamente, como punto de partida común a los otros autores, en considerar a El Capital una obra unilateral y parte de una obra más extensa.

Lebowitz, se coloca en la línea trazada por varios representantes del marxismo como son Gorz - quien argumenta que la idea de proletariado de Marx no se basa en la observación empírica; Castoriadis - quien considera que Marx se equivoca al comprender a la fuerza de trabajo como mercancía; Thompson -quien ve en El Capital, una lógica del capital, no del capitalismo, lo que deja sin considerar las dimensiones sociales; y al joven Marx en contra de Marx, al criticar la reducción que realiza la economía política clásica al capital (Lebowitz 2006, 81). Pero a diferencia de estos autores, Lebowitz se limita a considerar a El Capital como el punto de vista del capital y no el de los obreros (Lebowitz 2006, 84).

Según Lebowitz este silencio en torno a los obreros, expresión del "determinismo", "fatalismo", "reduccionismo" y "economicismo" de El Capital se sostiene en una premisa: considerar como dado, sin variación, el conjunto de las necesidades imprescindibles como 
parte del método de trabajo implementado por Marx (Lebowitz 2006, 109). Este es el punto de partida para el resto de la obra faltante. Más específicamente, marca el inicio del "libro sobre el trabajo asalariado" que eliminaría esta premisa (Lebowitz 2006, 110). Considera que, al igual que Rubel (Lebowitz 2006, 87), el plan de seis partes de los Grundrisse, las citas de la Contribución y otras menciones dispersas en la obra de Marx sobre un libro o doctrina del trabajo asalariado, suponen su necesaria contemplación por Marx. Pero lo más significativo no reside en el argumento marxológico, sino en su lectura sobre El Capital y su lugar en la obra de Marx. Lebowitz, al igual que Negri (Negri 2001), pero no así abiertamente Rubel (Rubel 2003), sugieren que el material para el libro sobre el trabajo asalariado es clave para comprender la teoría de Marx (Lebowitz 2006, 115). Según el canadiense: "El Capital no investiga el aspecto de la relación capital/trabajo asalariado que implica la creación de nuevas necesidades sociales para los trabajadores y sobre las cuales "descansa el actual poder del capital" (Lebowitz 2006, 119). No se ocupa de los cambios en el nivel de las necesidades que pueden nacer cuando el trabajador "presiona en sentido contrario" al capitalista en el curso de la lucha de clases. Este es el tipo de cuestiones que no se relacionan con el análisis del capital como tal, sino que fueron relegadas a la "investigación del trabajo asalariado en particular" (Ibíd.).

Para Lebowitz el capital está incompleto, es apenas una parte de la obra; por lo tanto, se trata de una obra parcial, unilateral, un enfoque limitado (Lebowitz 2006, 119). Lo que falta desarrollar es la parte del trabajo asalariado, algo que en El Capital sólo aparece de forma latente. En esta parte de la contradicción, del lado del capital, el obrero no es considerado como sujeto aún (Lebowitz 2006, 146). Para esto hace falta introducir la reproducción del obrero mismo en el proceso de conjunto. Es decir, junto a la valorización del capital nos encontramos con la reproducción del obrero. Este segundo ciclo productivo, diferente del capital, se regiría por intereses diversos a los de la valorización (Lebowitz 2006, 135). Mientras que en la valorización la fuerza de trabajo aparece como un valor de uso para el capital, en la reproducción del obrero es el capital en su forma de mercancía para el consumo un medio para sí. Mientras que en la valorización el proceso productivo está orientado por la necesidad de valorizarse, en la reproducción del obrero está guiado por su propia necesidad.

Tal como aparecería en la obra en cuestión, el capital y el trabajo a través del salario se contraponen como expresiones de necesidades antagónicas, una como esfera de la producción, la otra como la esfera de la reproducción. En la primera esfera el trabajo en general deviene ser-para-el-capital en la producción, pero para sí mismo en la reproducción (Lebowitz 2006, 238). Este afuera del capital es la fuente y explicación de las contradicciones que emanan de la acumulación capitalista. Tal contradicción aparecía aminorada por el autor de El Capital, como una forma de percibir los movimientos del capital lo menos perturbados posible. Sin embargo, al levantar el supuesto de las necesidades invariables, todas las conclusiones sacadas de El Capital quedarían relativizadas o contrapesadas por este nuevo campo no abordado por Marx: el de la fuerza de trabajo y su reproducción, sobre el cual es posible desarrollar una economía política del trabajo asalariado (Lebowitz 2006, 153) . 
El trabajo, ahora como una variable viva, se expresaría entonces como el límite a la jornada de trabajo, el desarrollo de la lucha política y todas las tendencias que minen la competencia que impone el deber ser del capital, tales como las cooperativas (con sus limitaciones), los sindicatos, etc., combatiendo esta tendencia intrínseca del capital a dividir a los obreros (Lebowitz 2006, 146). Las fuerzas materiales de la clase obrera no emanan de su "antagonista", sino de las necesidades humanas que no responden al mero ser del trabajador asalariado, considerado una abstracción por Lewobitz, una reducción propia del marxismo unilateral (Lebowitz 2006, 233) o economicista que sólo se basa en El Capital para extraer las determinaciones de la clase obrera, olvidando "este lado" de la totalidad social, "lo humano". Esta serie de necesidades propias de "lo humano" son las que se resisten a ser reducidas a una mera personificación. Este ser humano, siempre social, recoge una serie de necesidades, no sólo las impuestas por el capital o bien no reductibles a su valorización, sino que son necesidades sociales que están por sobre la necesidad de valorización, las que emergen, al parecer, de la mera conciencia de ser oprimidos por la valorización del capital.

Considerando esta falta en El Capital, su carácter unilateral, Lewobitz pretende usar el mismo método de Marx para completar la parte ausente. Por medio de lo que el economista llama "método de la derivación dialéctica" (Lebowitz 2006, 125), trata de continuar esta "derivación" hacia las formas que corresponderían a esta necesidad que se resiste a ser subsumida al capital. Es decir, considerando las inconsistencias de El capital, Lebowitz deduce "dialécticamente" que hay un elemento que no es parte de éste pero que necesita, demanda algo que le es exterior (Lebowitz 2006, 133). Un espacio donde el obrero se pertenece a sí mismo (Lebowitz 2006, 141) y es considerado como sujeto, mientras que en El Capital nunca lo es (Lebowitz 2006, 146). En tanto que no es sujeto en El Capital, se vuelve necesario un libro sobre sus propias determinaciones, distintas a las tratadas en la obra.

Más arriba habíamos mencionado la adherencia de Lebowitz a esta lectura de un Marx que habría quedado preso del encanto de la economía política criticada por él mismo, desarrollando una visión reducida de la clase obrera como siendo sólo para el capital. Retomando las críticas del joven Marx (Lebowitz 2006, 154), el canadiense pretende desarrollar una economía política que valore a la clase obrera como la potencia colectiva que impulsa al capital, como su otro, como aquello que el capital debe mantener vivo, porque depende de él, pero dividido, porque logra mantenerlo sometido a su necesidad de valorización. El viejo Marx, el Marx de El Capital, entonces, no sólo se olvidó de la mitad de la teoría, si no que nunca rompió con la economía política clásica (Lebowitz 2006, 188). Es más, El Capital -ahora una falsa crítica de la economía política-, es una representación defectuosa de la realidad (Lebowitz 2006, 235) que se puede reducir al estudio de la lógica del capital, separado de la clase obrera (Lebowitz 2006, 283).

En ese sentido, al igual que Negri, Thompson y varios autores que ven en El Capital una versión reducida o economicista de la clase obrera, esta representa un límite absoluto al 
capital, el otro del capital (Lebowitz 2006, 85). Si Marx no desarrolló en qué consiste este lado del conflicto, el libro de Lebowitz pretende explorarlo. Este otro del capital se presenta como conflicto o lucha de clases, esa tensión entre dos sujetos diferentes (Lebowitz 2006, 153), contrapuestos, que merma el conjunto de relaciones, incluyendo el salario. Este último no estaría determinado por el valor de las mercancías que entran en el consumo obrero, sino por la fuerza que aplica el trabajo en su lucha por apropiarse de más valores de uso de acuerdo a sus necesidades que se expanden junto con el capital. Este factor histórico moral sería la expresión de la lucha de clase dentro de El Capital, ya que es ésta la que define el patrón de necesidad (Lebowitz 2006, 205).

De ser así, de tratarse de un enfrentamiento de fuerzas exteriores mutuamente, deberíamos preguntarnos por la potencia de estas fuerzas, de dónde obtienen la capacidad material de ser tales. Al parecer, a partir de los planteamientos de Lebowitz esta pregunta no puede tener otra respuesta que su necesidad inmediata, la contraposición de un puro "deber ser" contra otro (Lebowitz 2006, 146). Por un lado, entonces, tenemos la necesidad inmediata del capital por valorizarse, por otro lado, la de los obreros que pujan por satisfacer sus necesidades independientes (auto valorizarse, por decirlo en la jerga de Negri). El problema de esto, aparte de lo que señalamos para Negri, es que el capital como modo de producción histórico pierde toda necesidad, se presenta como un abstracto antagonismo que depende del movimiento de la lucha o, en última instancia, de un deseo humano general que no es más que una abstracción al estar separado de su relación social concreta: el capital. Al igual que Negri, para Lebowitz el salario se presenta como el punto de "contacto", la relación concreta que toman estas dos fuerzas exteriores. Esto implica sustituir el contenido de la lucha de clases por la correlación de fuerzas que tiene su necesidad en el hecho de ser puramente antagónicas. Como se ve, se trata nuevamente de una tautología. Una inversión que coloca como fundamento de la relación social general (el capital) la relación directa entre personificaciones y, por tratarse de una relación exterior, la conciencia revolucionaria de la clase obrera queda reducida, nuevamente, a una pura necesidad ética fundada en la inmediatez de la conciencia enajenada, no como producto necesario del desarrollo de la misma relación social general.

\section{d. La unidad del trabajo asalariado y el capital}

Uno de los referentes obligados dentro de las varias lecturas en torno al problema de un libro sobre el trabajo asalariado es Roman Rodolsky. En su obra más conocida (Rodolsky 2004) le dedica varias páginas al problema.

$\mathrm{Su}$ consideración se sitúa desde una perspectiva que busca leer y comprender los Grundrisse a partir de El Capital, como una forma previa o menos desarrollada, en contraposición a las opiniones de los tres autores comentados anteriormente. Sin embargo, su lectura, igual que la de Lapides (Lapides 2008), tiene como eje un problema más bien filológico

Es así que a partir de la comparación de los diversos planes esbozados por Marx, Rodolsky plantea que de los seis libros planeados a fines de los 50s, esbozados tanto en los 
Grundrisse como en la Contribución, el libro sobre la propiedad de la tierra y del trabajo asalariado se integran al primero de éstos, donde Marx trata del "capital en general". Más específicamente, Rodolsky señala que la integración de estos temas que aparecían a parte en el plan de fines de los 50s, se realiza en los manuscritos de 1864-1866, reduciendo los libros planeados a El Capital (Rodolsky 2004, 37).

En ese sentido, la ausencia del desarrollo de esos temas en los Grundrisse obedece a la estructura del plan original, el cual cambiaría a principios de los 60s (1862-63), integrándolos. Esta idea se ve reforzada constatando que El Capital comprende aún más temas que no eran tratados en profundidad en los Grundrisse o sólo eran mencionados en estos borradores de fines de los 50s: cooperación, manufactura, gran industria, la acumulación originaria, etc., como así también los temas que debería incluir un libro sobre el trabajo asalariado (Rodolsky 2004, 46).

Esta ampliación del plan original implicaría no sólo la integración de los libros señalados en él, sino la integración de los temas de la competencia y otras formas que nos acercan a la superficie de la sociedad burguesa. En otras palabras, es esta misma expansión del capital que pasa del capital en general a formas más desarrolladas, lo que hace que Marx integre el libro del trabajo asalariado en El Capital, fundamentalmente en el Tomo I. Mientas que los otros tres libros pendientes quedarían relegados a un próximo desarrollo (Rodolsky 2004, 50).

Según Rodolsky, el plan de fines de los 50s será un modelo provisorio por medio del cual Marx desarrolló las “determinaciones puras” (Rodolsky 2004, 68). Para el polaco, “...si bien se les abandonó en cuanto secciones independientes, incorporando su contenido a la nueva estructura de la obra, [...] la estricta separación originaria de las categorías fue sólo un medio de abstracción metodológica y que por ello se la pudo abandonar apenas hubo llevado a cabo la tarea principal: el análisis del "capital en general"” (Rodolsky 2004, 69)

A nuestro parecer, Rodolsky reduce lo simple de las formas como "lo común" en todas ellas, lo que a veces vuelve confusa su forma de entender el método y las formas del capital "puro". Sin embargo, a pesar de esta falta de precisión, entiende que los otros temas ausentes son la forma desarrollada del capital en general, como son la competencia, la formación de la tasa de ganancia, etc.; todos fenómenos de la circulación (Rodolsky 2004, 78-79), y que se tratan en el Tomo III. Esto, si bien se enmarca en la discusión marxológica permite al autor establecer el carácter desarrollado de El Capital -que se acerca más a las formas concretas del capital, a sus manifestaciones superficiales- respecto de los Grundrisse -donde Marx se dedica al desarrollo del capital en general (Rodolsky 2004, 82). En otras palabras, integra los libros del trabajo asalariado y de la propiedad de la tierra a El Capital, pero, más importante aún, señala la diferencia específica entre las formas simples y desarrolladas pero de una manera abstracta. De todas maneras, ni un posible libro del trabajo asalariado o bien sobre la propiedad de la tierra trataría de formas esenciales, sino que sería el desarrollo de lo ya embrionario y más o menos desarrollado en El Capital (Rodolsky 2004, 80-81).

Entonces, considerando que El Capital parece ser una forma desarrollada de lo esbozado en los Grundrisse, el libro del trabajo asalariado se integra al Tomo I porque 
expresa, según Rodolsky, "un eslabón intermedio necesario entre la teoría del valor del tomo I y la teoría de los precios de la producción, a desarrollar en el tomo III" (Rodolsky 2004, 85). Pero así también, estos cambios en los planes, señala finalmente Rodolsky, demuestran que "la estricta separación entre las categorías del capital y del trabajo asalariado, tal como la preveía el plan antiguo, sólo resultaba viable hasta cierto punto" (Rodolsky 2004, 91), a partir del cual el plan debió ser abandonado.

Sin embargo, nos separamos de Rodolsky a la hora de considerar de forma más precisa estas extensiones del plan original, el desarrollo de sus formas más concretas, ya que confunde las partes llamadas "históricas" del capital -y que son parte extensa de, por ejemplo, la sección sobre el salario, pero así también de la ley general de acumulación capitalista-, como momentos de carácter ilustrativo y no como las formas desarrolladas del capital. Según el autor, "los resultados esenciales de la investigación que aparecen en las secciones mencionadas [...] también hubiesen podido exponerse sin necesidad de recurrir a ese material ilustrativo, cosa que durante años había sido la intención de Marx" (Rodolsky 2004, 90). Frente a este punto, concordamos con Caligaris a la hora de indicar que las partes que Rodolsky puede identificar como "ilustrativas", responden al desarrollo de formas más concretas bajo las cuales debe realizarse la necesidad contenida como potencia en la forma abstractas. Considerando lo tratado por el autor, la compra y venta de la fuerza de trabajo, la explotación de la fuerza de trabajo por parte del capitalista, se realiza necesariamente como lucha de clases (Caligaris 2012.), por lo que aquello que Rodolsky llama puro no puede ser reducido a su forma simple y solo se comprende como las formas concretas que toma su desarrollo. Finalmente, creemos que esta limitación en la comprensión del método, reduce el alcance de la observación de Rodolsky al limitar el problema del libro sobre el trabajo asalariado a un tema "marxológico", sin avanzar en las determinaciones de la potencialidad revolucionaria de la clase obrera, o al menos volviendo su relación una de carácter poco claro.

\section{e. Más allá de la interpretación de Marx}

Finalmente encontramos a Lapides quien, dentro de la tradición de autores marxistas, parece ser el que ha tratado con mayor rigor el tema del salario en la obra de Marx. En su trabajo más extenso (Lapides 2002) sostiene que El Capital contiene las determinaciones esenciales del salario. Haciendo referencia a lo esbozado por Marx en el capítulo XVIII del Tomo I, donde analiza el trabajo por tiempo -una de las formas concretas que adopta el salario y que expresa una modificación formal de las "leyes del salario" (Marx 2002, 661), Lapides plantea que "aquellos escritores que señalan que Marx reservaba el tratamiento de los salarios para un trabajo separado, aparentemente no han notado esta observación" (Lapides 2008, 196).

A partir de una revisión de El Capital, Lapides estima que Marx ha creado con éxito una "teoría" de los salarios. Dinámica, compleja y comprensiva, explica y predice los diversos fenómenos del salario, así como las principales tendencias de la relación capitaltrabajo (Lapides 2008, 207). 
En su opinión, la expresión "teoría del trabajo asalariado" que aparece incluso en $E l$ Capital estaría reservada "para los aspectos puramente fenoménicos del salario. Las "fricciones" reales, como las llamó, del mercado, tales como el engaño y la coerción que son inevitables en la economía capitalista pero no son intrínsecos a su dinámica interna" (Lapides 2008, 208). Esta distinción entre lo fenoménico y lo esencial vacía de necesidad a estas formas que son subordinadas de manera abstracta a la "dinámica interna" del capital, perdiendo de vista lo concreto.

Como ya señalamos, Lapides se ubica dentro de los marxistas que rechazan la idea de un trabajo ausente, "declarando que la teoría presente en El Capital y textos relacionados es, si es que no literalmente, al menos analíticamente completa" (Lapides 2008, 211). Según Lapides, esto se debería a un error en la interpretación de la transformación del plan de la obra, el cual parece haber quedado reducido al primero de los seis libros planteados a fines de los 50s, de ahí que falte el libro del trabajo asalariado y El Capital quede reducido a una teoría incompleta (Lapides 2008, 213).

Lapides recorre el debate desde Kautsky -que fue el primero en señalar la divergencia en los planes, pero sosteniendo el carácter acabado de la "teoría del salario"; Wilbrand -que es el primero en declarar el carácter incompleto de la obra de Marx, una parte de seis; Grossman -quien desde un punto un tanto más cercano al nuestro, contesta al segundo desde "la estructura interna" de El Capital, pero a quien también Lapides critica (Lapides 1997); Rubel -que revive los argumentos de Wilbrand; terminando con Lebowitz - a quien dedica un breve artículo (Lapides 2002) y McLellan -ambos sostienen esta idea de un libro faltante en la misma línea de Wilbrand-Rubel (Lapides 2008, 213-216). Sin embargo, a pesar de adherir a la idea de que el fundamento del salario está contenido en El Capital cae en la trampa de la marxología: "Para evaluar estas posiciones, el mejor camino es revisar primero la evolución misma del plan de Marx para escribir El Capital" (Lapides 2008, 216).

A pesar del carácter marxológico del ejercicio, Lapides concluye -como Rodolsky- que "la relación capital trabajo está puesta en el corazón del análisis" (Lapides 2008, 221) y señala que es a principios de los 60s donde Marx desarrolla por primera vez los elementos fundamentales de su teoría del salario (Lapides 2008, 222), confirmando el abandono del plan original y su integración a El Capital como forma desarrollada del capital.

Finalmente, avanzando en el impacto político del aporte científico de Marx, Lapides señala que la teoría del salario y del trabajo asalariado de Marx ha sido un elemento indispensable en el "arsenal ideológico" de la clase obrera: "pretender que no existe es intentar desarmar a los obreros negándoles esta parte de su legado" (Lapides 2002, 233). Sin embargo, nos parece que el análisis marxológico es insuficiente. Sostenemos que el aporte de Marx no es parte de un "arsenal ideológico" siendo el desarrollo científico del problema del trabajo asalariado. El éxito de Marx está en su capacidad para aportar al conocimiento en torno a las determinaciones del capital cuyo desarrollo tiene a la acción política de la clase obrera como medio de realizarse, por lo que debemos buscar una respuesta más consistente al problema que la pura marxología, avanzando en descubrir las potencias revolucionarias de la clase obrera que sólo puede sacar fuerza de su propia relación social. 


\section{La reproducción de la fuerza de trabajo y el capital}

A nuestro parecer, ninguno de los trabajos anteriores logra ser satisfactorio, bien porque separan la unidad de la relación social general, abstrayendo a la clase obrera de su propia condición material, o bien porque a pesar de concebir la unidad, reducen el problema a una discusión marxológica sin abordar el problema de la subjetividad revolucionaria de la clase obrera. Es por eso que se vuelve necesaria una tercera posición.

Todas las formas sociales necesitan reproducirse, es decir, necesitan que el proceso de producción sea continuo (Marx 2002, 695). Esto implica, por lo tanto, que del total social producido una parte debe ser continuamente reconvertida en medios de producción y otra en fuerza de trabajo. Sin embargo, esto no pasa de ser una afirmación general, común a todo modo de producción (Marx 1971, 8).

En el caso del modo de producción capitalista la producción tiene como finalidad la producción de valor y más específicamente de plusvalor, como forma específica de ampliar la capacidad de crear esta capacidad para organizar el trabajo social como atributo del producto material del trabajo anterior (Iñigo Carrera 2013, 12). Este proceso de valorización se reproduce, en su forma más simple, reproduciendo al obrero, por un lado y al capitalista por el otro, uno como poseedor de fuerza de trabajo, al otro como dueño de los medios de producción. De esta manera, al repartir el producto social necesario para volver echar a andar la producción, el capital dinero transmuta bajo la forma de capital constante y variable. El primero destinado a convertirse en medios de producción, el segundo, como el medio de producción más importante de todos: fuerza de trabajo que, una vez es puesta en movimiento, deviene trabajo vivo.

Al subsumir la circulación a la producción de plusvalor, el fondo de subsistencia destinado a la reproducción de la fuerza de trabajo se le presenta al obrero como medios de pago equivalentes a una determinada cantidad de valor intercambiable por medios de vida, los que se le aparecen como un enorme cúmulo de mercancías en la circulación.

Si ponemos nuestra atención a este último proceso, veremos al vendedor de la fuerza de trabajo que se presenta ante el comprador con la única mercancía que posee para participar de su relación social general. Al tratarse de una relación social indirecta mediada por mercancías, la circulación vela la emergencia del plusvalor al aparecer el valor de su fuerza de trabajo como salario o "valor del trabajo", quedando oculto a la vista del obrero el origen mismo de este monto, así como la parte que se embolsa el capitalista, dando la impresión de que, por un lado, el salario sale del bolsillo del capitalista y la ganancia del intercambio de mercancías vendidas al final del proceso. Es decir, el monto en dinero que desembolsa el capitalista y que intercambia por fuerza de trabajo aparece como una mera magnitud que pertenece al capitalista y que equivale al "valor del trabajo" proporcionado por el obrero. Pero, dejando de lado la perspectiva individual, el enfrentamiento directo entre vendedor y comprador de mercancías, el análisis de la reproducción simple hecho por Marx, deja al descubierto que, detrás del intercambio de equivalentes, donde el capitalista sólo devuelve, bajo la forma de salario, el trabajo producido por el obrero, se oculta la apropiación del 
plustrabajo creado en el proceso de producción que pone a funcionar con la fuerza de trabajo bajo su dominio, como un atributo del capital (Marx 2002, 695-713).

Este proceso de compra y venta -que se repite toda vez que el obrero se enfrenta al capitalista como poseedor de dinero- ocurre bajo ciclos más cortos que la circulación en general. A esta circulación Marx la denomina "pequeña circulación” (Marx 2005, 195 y sgts.). Dada la especificidad del modo de producción capitalista, la mercancía fuerza de trabajo, su circulación, se diferencia de la circulación en general, la que comprende todo el periodo en que el capital emerge y regresa al proceso de producción. A diferencia de esta última, la "pequeña circulación" "es continua y ocurre constantemente de manera simultánea con el proceso de producción. Es la parte del capital que se paga como salario, que se intercambia por la capacidad de trabajo" (Marx 2005, 195). De esta manera, la pequeña circulación es la que pone al capital en cuanto tal, al someter a la fuerza de trabajo a la valorización.

Ahora bien, la repetición constante de este proceso, supone la reproducción del obrero como algo a parte de las condiciones objetivas del trabajo, lo que conlleva a la separación del producto del trabajo y el trabajo mismo, condición fundamental del proceso capitalista de producción. Dicho de otra forma, en tanto proceso que se reproduce, "el capital produce en su reproducción sus propias condiciones" (Marx 2005, 198) lo que implica no sólo el destinar una parte del producto para la creación de más medios de producción (capital fijo), sino la fuerza de trabajo que, puesta junto a los medios de trabajo, los revive dando paso a la producción de plusvalor.

Desde esta perspectiva, al ser la relación social general la que reproduce sus condiciones de producción, el consumo del obrero adquiere un sentido muy diferente al que se nos presentaba desde la perspectiva del obrero individual. Ahora, considerando el proceso de reproducción en su conjunto, bajo sus determinaciones más simples, "la clase capitalista entrega constantemente a la clase obrera, bajo la forma dineraria, asignados sobre una parte del producto creado por esta última clase y apropiado por la primera" (Marx 2002, 697). Pero así también, "el obrero devuelve a la clase capitalista esos asignados y obtiene de ésta, así, la parte que le corresponde de su propio producto. La forma mercantil del producto y la forma dineraria de la mercancía disfrazan la transacción.” (Ibíd.).

Si consideramos sólo el proceso de producción, el consumo del obrero aparecía como un proceso que se realiza por fuera de la circulación, como consumo individual o improductivo, por "fuera del capital". Ahora, desde la perspectiva de la reproducción, este aparece como improductivo solo para él, mientras que, desde la reproducción de la relación social general, aparece productivo para el capital, no como plusvalor, sino como la renovación constante de la valorización, como condición de sí mismo (Marx 2002, 198)..

Por lo tanto, si bien el obrero puede consumir improductivamente su salario, el capital lo consume a él de manera productiva, por lo que el consumo del obrero aparece como un momento necesario de la propia valorización y no, como pretenden algunos, como autovalorización del obrero. 
La importancia de subsumir realmente la fuerza de trabajo al capital, radica en que, al hacerlo, el capital se apropia del proceso humano genérico de trabajo, portado por los individuos, sometiéndolos a las necesidades de la valorización. La fuerza de trabajo, que debe ser producida y reproducida, ahora lo hace de una manera específicamente capitalista al ser el medio por el cual el capital se valoriza. Dicho de otra manera, la capacidad genérica del ser humano - portada por los individuos- aparece invertida a la conciencia libre de los individuos como una capacidad social ajena y que los somete.

Su conciencia libre, que media su consumo individual, se muestra desvinculada de la producción, de la misma forma que su sujeción al conjunto de la clase capitalista se oculta detrás del contrato de trabajo y la relación con los capitalistas individuales. Sin embargo, la reproducción y continuación del proceso, sólo reafirma la subordinación real del obrero al capital, como forma y condición del mismo tal como con los medios de producción. El obrero, entonces,

se suministra medios de subsistencia, para mantener en funcionamiento su fuerza de trabajo, de la misma manera que se suministran carbón y agua a la máquina de vapor, aceite a la rueda, etcétera. Sus medios de consumo son entonces meros medios de consumo de un medio de producción, y su consumo individual pasa directamente a ser consumo productivo. Esto, no obstante, se manifiesta como un abuso accidental del proceso capitalista de producción" (Marx 2002, 703).

Por lo tanto,

...el consumo individual del obrero sigue siendo también un elemento de la producción y reproducción del capital, ya se efectúe dentro o fuera del taller, de la fábrica, etc., dentro o fuera del proceso laboral; exactamente al igual que lo que ocurre con la limpieza de la máquina, ya se efectúe dicha limpieza durante el proceso de trabajo o en determinadas pausas del mismo. El hecho de que el obrero efectúe ese consumo en provecho de sí mismo y no para complacer al capitalista, nada cambia en la naturaleza del asunto. De la misma suerte, el consumo de la bestia de carga no deja de ser un elemento necesario del proceso de producción porque el animal disfrute de lo que come. La conservación y reproducción constantes de la clase obrera siguen siendo una condición constante para la reproducción del capital. El capitalista puede abandonar confiadamente el desempeño de esa tarea a los instintos de conservación y reproducción de los obreros (Marx 2002, 703-704).

Ahora bien, no solo el consumo del obrero aparece como una condición necesaria y puesta por el capital mismo, sino que la misma conciencia libre del obrero se descubre como una forma concreta de su conciencia enajenada, la forma específica que media su reproducción, y con ello, la reproducción del capital (Marx 2002, 705).

Despojado de los medios para producir su vida, cada vez que abandona el proceso de producción tal como entra en él: solo poseyendo su fuerza de trabajo, necesitando reproducirla para volver a subordinarse a otro. Desde esta perspectiva, su consumo individual es improductivo, no genera plusvalor alguno. Pero desde la perspectiva del capital 
en su conjunto tal reproducción es productiva para el capital en su conjunto. Por lo tanto, aquello que desde la perspectiva individual parece bajo determinada forma, se invierte al considerar al capital como una relación social general. Tal como señala Marx,

el consumo individual del obrero es improductivo para él mismo, puesto que únicamente reproduce al individuo lleno de necesidades, es productivo para el capitalista y el estado, puesto que es producción de la fuerza que produce la riqueza ajena" (Marx 2002, 706).

Por lo tanto

Desde el punto de vista social, la clase obrera, también cuando está fuera del proceso laboral directo es un accesorio del capital, a igual título que el instrumento inanimado de trabajo. Incluso su consumo individual no es, dentro de ciertos límites, más que un factor del proceso de reproducción del capital. Pero el proceso vela para que esos instrumentos de producción autoconscientes no abandonen su puesto, y para ello aleja constantemente del polo que ocupan, hacia el polo opuesto ocupado por el capital, el producto de aquéllos. El consumo individual, de una parte, vela por su propia conservación y reproducción, y de otra parte, mediante la destrucción de los medios de subsistencia, cuida de que los obreros reaparezcan constantemente en el mercado de trabajo. El esclavo romano estaba sujeto por cadenas a su propietario; el asalariado lo está por hilos invisibles. El cambio constante de patrón individual y la fictio juris [ficción jurídica] del contrato, mantienen en pie la apariencia de que el asalariado es independiente" (Ibíd.).

Esta ficción jurídica -que tiene al contrato como su forma más simple (Marx 2002, 103)-, una vez atravesada su apariencia permite ver que "el obrero pertenece al capital aun antes de venderse al capitalista. Su servidumbre económica está a la vez mediada y encubierta por la renovación periódica de la venta de sí mismo, por el cambio de su patrón individual y la oscilación que experimenta en el mercado el precio del trabajo" (Marx 2002, 711-712).

De esta manera, el proceso de producción capitalista ha quedado determinado no sólo como proceso de producción plusvalor, sino que

El proceso capitalista de producción, considerado en su interdependencia o como proceso de reproducción, pues, no sólo produce mercancías, no sólo produce plusvalor, sino que produce y reproduce la relación capitalista misma: por un lado el capitalista, por la otra el asalariado" (Marx 2002, 712).

Para la mayoría de los autores vistos, este proceso unitario aparece como algo separado del capital, como el espacio de reproducción del obrero, realizado de acuerdo a sus propias necesidades (u otras diferentes a la valorización). La clase obrera no es una forma del capital sino que es dominada por él, como una relación exterior, quedando limitadas a las apariencias, prisioneras "de las representaciones en las cuales se mueven los agentes del modo capitalista de producción” (Marx 1972, 3-4). 
Pretender que el capital expresa una "lógica" o una "necesidad" diferente a la de la clase obrera es justamente romper este proceso reproductivo, es decir, dejar de concebir al capital como unidad, como la relación social general dentro de la cual los seres humanos producen y reproducen su vida, transformando así a la clase obrera en una abstracción, dejándola impotente, privada de sus potencias históricas.

\section{2. ¿Más allá de Marx y de El Capital?}

Al parecer, los intentos de Negri, Rubel y Lebowitz tienen la intención de colocar en el centro de la cuestión la lucha de las clases, rescatar la autonomía de la clase obrera y desmarcarse de las visiones "unilaterales" o "economicistas". Tanto Lebowitz como Negri, teniendo como referencia las observaciones de Rubel y otros ex o "post" marxistas, buscan los límites del capital en El Capital para seguir el rastro al supuesto gran ausente de su obra magna: los obreros. Sin embargo, pierden de vista que la clase obrera es tal en la medida que vive subordinada como un atributo al capital, el cual, como relación social general, no sólo produce plusvalor, sino los seres humanos necesarios para producirlo. La subsunción real del proceso de trabajo al capital implica no sólo subordinar la fuerza de trabajo, sino el proceso de vida genérico humano, el que aparece invertido a los obreros enajenado como una potencia del capital. Es bajo la forma capitalista en que el metabolismo social general se realiza. Nos enfrentamos entonces a que el corazón de la clase obrera late al ritmo del mismo capital.

Al considerar que la relación que establece la clase obrera con el capital es "exterior", se ven obligados a buscar un "afuera" de la relación social general donde se desarrollen las potencias subjetivas que, según estos autores, el capital niega, quedando presos de la conciencia abstractamente libre. Buscan "salir del capital" por medio del análisis del salario al momento de determinar la relación entre la parte necesaria y no retribuida de la jornada y suponen que su contenido es una abstracta lucha de clases. Su misma preocupación por los asuntos de la clase obrera termina por negarle a esta su propia condición de ser, al separar el desarrollo de su subjetividad revolucionaria de su propia condición material, negándole su potencial revolucionario.

Tanto Lebowitz como Negri esperan que la clase obrera alcance una fuerza de tal dimensión que pueda invertir la situación y ser ella quien domine al capital en el mejor de los casos, o bien, se limite a ser una pura multitud impotente que quiere hace la revolución sin tomar el poder, en el peor. En lugar de ser la forma concreta en que la relación social indirecta mediada por mercancías recobra su unidad bajo la forma política, la lucha de clases, se reduce a una simple relación exterior, como el choque de dos fuerzas que encuentran su necesidad de manera contrapuesta, de forma indeterminada. Es decir, como intereses antagónicos simplemente inmediatos, sin poder explicar lo que expresan como formas concretas en que se realizan las formas más abstractas que contienen.

El problema de un libro que trate sobre una teoría del salario ha pasado de ser un tema "filológico" a un problema político sobre los intereses objetivos de la clase obrera, es decir, sobre las potencias que impulsan sus luchas, la materialidad que contienen. Suponiendo que 
"no se trata de lo que directamente se imagine tal o cual proletario, o incluso el proletariado entero. Se trata de lo que es y de lo que históricamente se verá obligado a hacer por ese ser" (Marx y Engels 1967, 102). Aquellas ciencias sociales que pretenden justificar a la clase obrera como una fuerza "independiente" y contradictoria con el capital la terminan vaciando de contenido. Para este marxismo "abierto", será la conciencia la que aparece como un punto irreductible al capital, como conciencia libre, como mera certeza inmediata de no ser el capital. Por lo tanto, como ciencia de la apariencia, estas posiciones no pueden ser sino ideología, expresando un contenido diferente al que dicen portar.

El capital, como forma histórica que asume la necesidad genérica propia de la vida natural humana, siguiendo su propia valorización, debe reproducir las condiciones que hacen posible la realización del plusvalor. En tanto forma privada del trabajo social mediado por el intercambio de mercancías, la forma más simple de dicha relación (la mercancía) que emerge en el proceso de circulación, se desarrolla como la reproducción constante de la separación entre obreros y capitalistas, por lo que los primeros no pueden tener más potencia que la que les entrega su propia relación social. Es decir, el capital, como relación social enajenada, es condición de su propia superación.

De acuerdo con Marx, la potencialidad de la clase obrera, su carácter revolucionario, no es una forma contraria al desarrollo del capital mismo, su "antagonista" o su "otro". Al contrario, comprender qué es el capital es comprender la forma concreta en que se produce y reproduce nuestra relación social general, conocer lo que el proceso de producción y reproducción del capital, como continuo proceso de desarrollo de las fuerzas productivas, impone fundando las condiciones de nuestra propia acción. Si el capital continúa pujando por desarrollarse y crecer, buscando abandonar definitivamente su crisálida, deberá "empujar" a la clase obrera a la lucha revolucionaria. Sin embargo, al adoptar las mismas potencialidades sociales de forma enajenada, dicha potencia no puede sino aparecerle como antagónica. Desde tal perspectiva, como sostiene Iñigo Carrera, Marx ha sido el primero en reproducir en El Capital, esa conciencia enajenada al tanto de su propia enajenación y las potencias históricas que contiene. ${ }^{8}$

Sin embargo, esta necesidad histórica se realiza de manera contradictoria. La condición fundamental de una organización consciente del trabajo es la revolución constante del proceso de producción, la que se materializa como nuevos medios de producción. Sin embargo, a diferencia de lo que pasa en su forma manufacturera, bajo el desarrollo del plusvalor relativo son los medios de producción los que subordinan al obrero como un mero apéndice. El desarrollo de la capacidad genérica humana del trabajo bajo su forma capitalista, es decir, como un medio para la valorización, se expresa como una permanente

\footnotetext{
${ }^{8}$ Según Juan Iñigo, “El Capital de Marx es en sí mismo el desarrollo, realizado por primera vez y puesto bajo una forma que permite su reproducción social, de la conciencia enajenada de la clase obrera que se produce a sí misma como una conciencia enajenada que conoce su propia enajenación y las potencias históricas que obtiene de ella. En El capital, esta conciencia se despliega hasta alcanzar sus determinaciones generales que conciernen a la acción revolucionaria de la clase obrera en la que dichas potencias históricas se realizan produciendo las condiciones materiales para la organización consciente -por lo tanto, libre- de la vida social" (Iñigo Carrera 2013, 41-42).
} 
expansión de esta capacidad genérica, desarrollada como una serie de trabajos concretos distribuido en un número de capitales individuales por medio de los cuales se realiza la valorización. Estas formas concretas, ahora formas del capital, se desarrollan como expresiones fragmentadas de la búsqueda de plusvalor relativo, como competencia entre capitales. La misma búsqueda de plusvalor impacta en el desarrollo de las fuerzas materiales que determinan la potencia de la clase obrera, pero también a la clase capitalista, cada una como personificación del propio desarrollo de esta relación social general. Al ser una totalidad fragmentada en una serie de unidades que producen privadamente, se ve en la necesidad de realizarse como relación social directa que establece las clases que personifican esas potencias, es decir, bajo la forma de lucha de clases y hace de la acción política de la clase obrera condición de realización de sus potencialidades y consiguiente superación.

La valorización, el impulso que mueve al capital como conjunto, desarrolla las fuerzas productivas a niveles nunca antes vistos, concentra el capital y coloca a la clase obrera como el único sujeto capaz de seguir desarrollando tales potencialidades. Ella es, no sólo la condición de su reproducción y desarrollo, sino que, por ser aquello que es, se vuelve palanca de su superación. Por lo tanto, lejos de ser una pura fuerza abstracta, la clase obrera se vuelve un eslabón en el proceso natural humano que se desarrolla por medio de la apropiación del entorno y, con ello, se desarrolla a sí mismo, teniendo cada vez más su propia acción consciente como forma necesaria de realización de tales potencialidades. Como señala Marx casi al final del Tomo I,

No bien ese proceso de transformación [que impone la propiedad capitalista, que depende del trabajo asalariado, G.R.] ha descompuesto suficientemente, en profundidad y en extensión, la vieja sociedad; no bien los trabajadores se han convertido en proletarios y sus condiciones de trabajo en capital; no bien el modo de producción capitalista puede andar ya sin andaderas, asumen una nueva forma la socialización ulterior del trabajo y la transformación ulterior de la tierra y de otros medios de producción en medios de producción socialmente explotados, y por ende en medios de producción colectivos, y asume también una nueva forma, por consiguiente, la expropiación ulterior de los propietarios privados. El que debe ahora ser expropiado no es ya el trabajador que labora por su propia cuenta, sino el capitalista que explota a muchos trabajadores." (Marx 2002, 952-953).

La necesidad de reducir el trabajo necesario al mínimo, ampliando el tiempo de plustrabajo y buscando la máxima valorización, transmuta por medio de su reproducción ampliada hacia una forma diferente de organizar la producción social total. La valorización sienta las bases de su propia desaparición. El capital, como forma de organizar el trabajo social total abre paso a una nueva forma concreta, una nueva relación social general. Esta no puede provenir del exterior, producto de una impredecible lucha de clases cuyos avances y retrocesos parecen condicionar los ciclos de acumulación. El proceso social de producción que se realiza como su opuesto, como conjunto de trabajos privados, transmuta, siguiendo su necesidad, en la organización directa de la producción social total bajo la forma de la lucha de clases. 
De todas maneras, el capital como su propia negación, continuamente busca apropiarse de la subjetividad productiva del obrero, objetivándola en máquinas que desplazan a más obreros; así también, utiliza todo el tiempo liberado producto de la reducción del trabajo necesario como tiempo para crear plusvalor, intensifica la explotación del trabajo e incrementa la población sobrante desplazada por la misma acumulación. Pero eso no contradice que la acción política de la clase obrera sea la forma en que se realizan sus potencialidades, es la forma concreta del mismo desarrollo de aquellas.

Lamentablemente la muerte impide a Marx seguir avanzando en el análisis sobre las formas desarrolladas del valor: Estado y mercado mundial, el primero como forma concreta que toma la inserción en el segundo, y sobre las formas que adopta la lucha de clases a partir del desarrollo de estas determinaciones. Sin embargo, reproducir tales formas hasta dar con la acción de la clase obrera como la manifestación concreta de realización de dichas potencialidades, no es problema de Marx, sino nuestro. Centrar la discusión en qué habría o no dicho Marx al respecto de tal o cual forma desarrollada, no tiene sentido, salvo que sea como un acto de reconocimiento social para trazarnos un punto de partida original. Sin embargo, su necesidad sólo se explica abordando estas mismas formas concretas, avanzando sobre las apariencias que enfrentamos, única forma, por lo demás, de verificar la vigencia de todo el recorrido hecho hasta acá. En otras palabras, se trata de avanzar en el conocimiento dialéctico de nuestra propia acción política por medio de la apropiación virtual de las contradicciones de la realidad actual (Iñigo Carrera 2013, 274), dejando de buscar la necesidad de la lucha de la clase obrera "por fuera" del capital.

\section{Referencias:}

Caligaris, G. (2012.). Clases sociales, lucha de clases y Estado en el desarrollo de la crítica de la economía política. En G. Caligaris, \& A. Fitzsimons, Relaciones económicas y políticas : aportes para el estudio de su unidad con base en la obra de Karl Marx (págs. 72-91). Buenos Aires: Universidad de Buenos Aires. Facultad de Ciencias Económicas.

Grossmann, H. (1979). La ley de la acumulación y el derrumbe del sistema capitalista. México: Siglo XXI Editores.

Grossmann, H. (2013). The Change in the Original Plan for Marx's Capital and Its Causes. Historical Materialism $n^{\circ} 21$ (3), 138-164.

Iñigo Carrera, J. (2007). Conocer el capital hoy. Usar críticamente El Capital. Vol 1: La mercancía, o la conciencia libre como forma de la conciencia enajenada. Buenos Aires: Imago Mundi.

Iñigo Carrera, J. (2013). El Capital: razón histórica, sujeto revolucionario y conciencia. Buenos Aires: Imago Mundi.

Lapides, K. (1997). Grossmann's model of capitalist breakdown: a false view of Marx's wage theory. Science \& Society; vol. 61, No 2, Summer, 229-236. 
Lapides, K. (2002). Marx’s doctrine of wage labor. Science \& Society, Vol. 66, Summer, 256-263.

Lapides, K. (2008). Marx's Wage Theory in Historical Perspective. Arizona: Wheatmark.

Lebowitz, M. (1992). The "Book on Wage-Labor" and Marxist. Science \& Society 57(1), 66-73.

Lebowitz, M. (2006). Más allá de El Capital. La economía política de la clase obrera en Marx. Caracas: Monteávila Editores.

Marx, K. (1971). Elementos fundamentales para la crítica de la economía política (Grundrisse) 1857-1859 Vol 1. Buenos Aires: Siglo XXI.

Marx, K. (1972). El Capital, Tomo I, Capítulo VI (Inédito). Buenos Aires: Siglo veintiuno editores.

Marx, K. (2002). El Capital, Tomo I, El proceso de producción capitalsita. Argentina: Siglo XXI editores.

Marx, K. (2002). Elementos fundamentales para la crítica de la economía política (Grundrisse) 1857-1858. Vol. 3. México: Siglo XXI editores.

Marx, K. (2005). Elementos fundamentales para la crítica de la economía política (Grundrisse) 1857-1858. Vol 2. Siglo Veintiuno Editores.

Marx, K., \& Engels, F. (1967). La Sagrada familia. México, D. F.: Juan Grijalbo Editor.

Negri, A. (2001). Marx más allá de Marx. Akal.

Rodolsky, R. (2004). Genesis y estructura de El Capital de Marx. México, D.F.: Siglo XXI.

Rubel, M. (1968). Reflexiones sobre utopía y revolución. En E. Fromm, \& y. otros, Humanismo Socialista (págs. 232-241). Buenos Aires: Paidos.

Rubel, M. (2003). Marx sin mito. Barcelona: Octaedro.

Rubel, M. (2012). Karl Marx: Ensayo de Biografía Intelectual. Buenos Aires: Ediciones ryr.

Sartelli, E. (2012). Una lectura "higénica". Maximilien Rubel y su Marx en clave ética. En M. Rubel, Karl Marx: ensayo de biografía intelectual. (pág. 20). Buenos Aires: Ediciones ryr.

Starosta, G. (2015). Marx's Capital, Method and Revolutionary Subjectivity. Boston: Brill. 